\title{
CONVENIO MARCO DE LA OMS PARA EL CONTROL DEL TABACO
}

\section{PREÁMBULO}

Las Partes en el presente Convenio,

Determinadas a dar prioridad a su derecho de proteger la salud pública,

Reconociendo que la propagación de la epidemia de tabaquismo es un problema mundial con graves consecuencias para la salud pública, que requiere la más amplia cooperación internacional posible y la participación de todos los países en una respuesta internacional eficaz, apropiada e integral,

Teniendo en cuenta la inquietud de la comunidad internacional por las devastadoras consecuencias sanitarias, sociales, económicas y ambientales del consumo de tabaco y de la exposición al humo de tabaco en el mundo entero,

Seriamente preocupadas por el aumento del consumo y de la producción de cigarrillos y otros productos de tabaco en el mundo entero, particularmente en los países en desarrollo, y por la carga que ello impone en las familias, los pobres y en los sistemas nacionales de salud,

Reconociendo que la ciencia ha demostrado inequívocamente que el consumo de tabaco y la exposición al humo de tabaco son causas de mortalidad, morbilidad y discapacidad, y que las enfermedades relacionadas con el tabaco no aparecen inmediatamente después de que se empieza a fumar o a estar expuesto al humo de tabaco, o a consumir de cualquier otra manera productos de tabaco,
Reconociendo además que los cigarrillos $\mathrm{y}$ algunos otros productos que contienen tabaco están diseñados de manera muy sofisticada con el fin de crear y mantener la dependencia, que muchos de los compuestos que contienen y el humo que producen son farmacológicamente activos, tóxicos, mutágenos y cancerígenos, y que la dependencia del tabaco figura como un trastorno aparte en las principales clasificaciones internacionales de enfermedades,

Reconociendo también que existen claras pruebas científicas de que la exposición prenatal al humo de tabaco genera condiciones adversas para la salud y el desarrollo del niño,

Profundamente preocupadas por el importante aumento del número de fumadores y de consumidores de tabaco en otras formas entre los niños y adolescentes en el mundo entero, y particularmente por el hecho de que se comience a fumar a edades cada vez más tempranas,

Alarmadas por el incremento del número de fumadoras y de consumidoras de tabaco en otras formas entre las mujeres y las niñas en el mundo entero y teniendo presente la necesidad de una plena participación de la mujer en todos los niveles de la formulación y aplicación de políticas, así como la necesidad de estrategias de control del tabaco específicas en función del género,

Nota: Puede que se introduzcan modificaciones sin importancia en la redacción del texto que la Asamblea de la Salud tiene ante sí, en cuyo caso se prepararía un corrigendum. 
Profundamente preocupadas por el elevado número de miembros de pueblos indígenas que fuman o de alguna otra manera consumen tabaco,

Seriamente preocupadas por el impacto de todas las formas de publicidad, promoción y patrocinio encaminadas a estimular el consumo de productos de tabaco,

Reconociendo que se necesita una acción cooperativa para eliminar toda forma de tráfico ilícito de cigarrillos y otros productos de tabaco, incluidos el contrabando, la fabricación ilícita y la falsificación,

Reconociendo que el control del tabaco en todos los niveles, y particularmente en los países en desarrollo y en los países con economías en transición, necesita de recursos financieros y técnicos suficientes adecuados a las necesidades actuales y previstas para las actividades de control del tabaco, Reconociendo la necesidad de establecer mecanismos apropiados para afrontar las consecuencias sociales y económicas que tendrá a largo plazo el éxito de las estrategias de reducción de la demanda de tabaco,

Conscientes de las dificultades sociales y económicas que pueden generar a mediano y largo plazo los programas de control del tabaco en algunos países en desarrollo o con economías en transición, y reconociendo la necesidad de asistencia técnica y financiera en el contexto de las estrategias de desarrollo sostenible formuladas a nivel nacional,

Conscientes de la valiosa labor que sobre el control del tabaco llevan a cabo muchos Estados y destacando el liderazgo de la Organización Mundial de la Salud y los esfuerzos desplegados por otros organismos y órganos del sistema de las Naciones Unidas, así como por otras organizaciones intergubernamentales internacionales y regionales en el establecimiento de medidas de control del tabaco,
Destacando la contribución especial que las organizaciones no gubernamentales y otros miembros de la sociedad civil no afiliados a la industria del tabaco, entre ellos órganos de las profesiones sanitarias, asociaciones de mujeres, de jóvenes, de defensores del medio ambiente y de consumidores e instituciones docentes y de atención sanitaria, han aportado a las actividades de control del tabaco a nivel nacional e internacional, así como la importancia decisiva de su participación en las actividades nacionales e internacionales de control del tabaco,

Reconociendo la necesidad de mantener la vigilancia ante cualquier intento de la industria del tabaco de socavar o desvirtuar las actividades de control del tabaco, y la necesidad de estar informados de las actuaciones de la industria del tabaco que afecten negativamente a las actividades de control del tabaco,

Recordando el artículo 12 del Pacto Internacional de Derechos Económicos, Sociales y Culturales, adoptado por la Asamblea General de las Naciones Unidas el 16 de diciembre de 1966, en el que se declara que toda persona tiene derecho al disfrute del más alto nivel posible de salud física y mental,

Recordando asimismo el preámbulo de la Constitución de la Organización Mundial de la Salud, en el que se afirma que el goce del grado máximo de salud que se pueda lograr es uno de los derechos fundamentales de todo ser humano sin distinción de raza, religión, ideología política o condición económica o social,

Decididas a promover medidas de control del tabaco basadas en consideraciones científicas, técnicas y económicas actuales y pertinentes,

Recordando que en la Convención sobre la eliminación de todas las formas de discriminación contra la mujer, adoptada por la 
Asamblea General de las Naciones Unidas el 18 de diciembre de 1979, se establece que los Estados Partes en dicha Convención adoptarán medidas apropiadas para eliminar la discriminación contra la mujer en la esfera de la atención médica,

Recordando además que en la Convención sobre los Derechos del Niño, adoptada por la Asamblea General de las Naciones Unidas el 20 de noviembre de 1989, se establece que los Estados Partes en dicha Convención reconocen el derecho del niño al disfrute del más alto nivel posible de salud,

Han acordado lo siguiente:

\section{PARTE I: INTRODUCCIÓN}

\section{Artículo 1}

\section{Lista de expresiones utilizadas}

Para los efectos del presente Convenio:

a) «comercio ilícito» es toda práctica o conducta prohibida por la ley, relativa a la producción, envío, recepción, posesión, distribución, venta o compra, incluida toda práctica o conducta destinada a facilitar esa actividad;

b) una «organización de integración económica regional» es una organización integrada por Estados soberanos a la que sus Estados Miembros han traspasado competencia respecto de una diversidad de asuntos, inclusive la facultad de adoptar decisiones vinculantes para sus Estados Miembros en relación con dichos asuntos; 1

c) por «publicidad y promoción del tabaco» se entiende toda forma de comunicación, recomendación o acción comercial con el fin, el efecto o el posible efecto de promover directa o indirectamente un producto de tabaco o el uso de tabaco; d) el «control del tabaco» comprende diversas estrategias de reducción de la oferta, la demanda y los daños con objeto de mejorar la salud de la población eliminando o reduciendo su consumo de productos de tabaco y su exposición al humo de tabaco;

e) la «industria tabacalera» abarca a los fabricantes, distribuidores mayoristas e importadores de productos de tabaco;

f) la expresión «productos de tabaco» abarca los productos preparados totalmente o en parte utilizando como materia prima hojas de tabaco y destinados a ser fumados, chupados, mascados o utilizados como rapé;

1. Cuando proceda, el término «nacional» se referirá a las organizaciones de integración económica regionales.

g) por «patrocinio del tabaco» se entiende toda forma de contribución a cualquier acto, actividad o individuo con el fin, el efecto o el posible efecto de promover directa o indirectamente un producto de tabaco o el uso de tabaco.

\section{Artículo 2}

\section{Relación entre el presente Convenio y otros acuerdos e instrumentos jurídicos}

1. Para proteger mejor la salud humana, se alienta a las Partes a que apliquen medidas que vayan más allá de las estipuladas por el presente Convenio y sus protocolos, y nada en estos instrumentos impedirá que una Parte imponga exigencias más estrictas que sean compatibles con sus disposiciones y conformes al derecho internacional.

2. Las disposiciones del Convenio y de sus protocolos no afectarán en modo alguno al derecho de las Partes a concertar acuerdos bilaterales o multilaterales, incluso acuerdos regionales o subregionales, sobre cuestiones relacionadas con el Convenio y sus protoco- 
los o sobre cuestiones adicionales, a condición de que dichos acuerdos sean compatibles con sus obligaciones establecidas por el presente Convenio y sus protocolos. Las Partes interesadas notificarán esos acuerdos a la Conferencia de las Partes por conducto de la Secretaría.

\section{PARTE II: OBJETIVO, PRINCIPIOS BÁSICOS Y OBLIGACIONES GENERALES}

\section{Artículo 3 \\ Objetivo}

El objetivo de este Convenio y de sus protocolos es proteger a las generaciones presentes y futuras contra las devastadoras consecuencias sanitarias, sociales, ambientales y económicas del consumo de tabaco y de la exposición al humo de tabaco proporcionando un marco para las medidas de control del tabaco que habrán de aplicar las Partes a nivel nacional, regional e internacional a fin de reducir de manera continua y sustancial la prevalencia del consumo de tabaco y la exposición al humo de tabaco.

\section{Artículo 4}

\section{Principios básicos}

Para alcanzar los objetivos del Convenio y de sus protocolos y aplicar sus disposiciones, las Partes se guiarán, entre otros, por los principios siguientes:

1. Todos deben estar informados de las consecuencias sanitarias, la naturaleza adictiva y la amenaza mortal del consumo de tabaco y de la exposición al humo de tabaco y se deben contemplar en el nivel gubernamental apropiado medidas legislativas, ejecutivas, administrativas u otras medidas para proteger a todas las personas del humo de tabaco.
2. Se requiere un compromiso político firme para establecer y respaldar, a nivel nacional, regional e internacional, medidas multisectoriales integrales y respuestas coordinadas, tomando en consideración lo siguiente:

a) la necesidad de adoptar medidas para proteger a todas las personas de la exposición al humo de tabaco;

b) la necesidad de adoptar medidas para prevenir el inicio, promover y apoyar el abandono y lograr una reducción del consumo de productos de tabaco en cualquiera de sus formas;

c) la necesidad de adoptar medidas para promover la participación de las personas y comunidades indígenas en la elaboración, puesta en práctica y evaluación de programas de control del tabaco que sean socialmente y culturalmente apropiados para sus necesidades $\mathrm{y}$ perspectivas; $\mathrm{y}$

d) la necesidad de adoptar medidas para que, cuando se elaboren estrategias de control del tabaco, se tengan en cuenta los riesgos relacionados específicamente con el género.

3. La cooperación internacional, particularmente la transferencia de tecnología, conocimientos y asistencia financiera, así como la prestación de asesoramiento especializado, con el objetivo de establecer y aplicar programas eficaces de control del tabaco tomando en consideración los factores culturales, sociales, económicos, políticos y jurídicos locales es un elemento importante del presente Convenio.

4. Se deben adoptar a nivel nacional, regional e internacional medidas y respuestas multisectoriales integrales para reducir el consumo de todos los productos de tabaco, a fin de prevenir, de conformidad con los principios de la salud pública, la incidencia de 
las enfermedades, la discapacidad prematura y la mortalidad debidas al consumo de tabaco y a la exposición al humo de tabaco.

5. Las cuestiones relacionadas con la responsabilidad, según determine cada Parte en su jurisdicción, son un aspecto importante del control total del tabaco.

6. Se debe reconocer y abordar la importancia de la asistencia técnica y financiera para ayudar a realizar la transición económica a los cultivadores y trabajadores cuyos medios de vida queden gravemente afectados como consecuencia de los programas de control del tabaco, en las Partes que sean países en desarrollo y en las que tengan economías en transición, y ello se debe hacer en el contexto de estrategias nacionales de desarrollo sostenible.

7. La participación de la sociedad civil es esencial para conseguir el objetivo del Convenio y de sus protocolos.

\section{Artículo 5}

\section{Obligaciones generales}

1. Cada Parte formulará, aplicará, actualizará periódicamente y revisará estrategias, planes y programas nacionales multisectoriales integrales de control del tabaco, de conformidad con las disposiciones del presente Convenio y de los protocolos a los que se haya adherido.

2. Con ese fin, cada Parte, con arreglo a su capacidad:

a) establecerá o reforzará y financiará un mecanismo coordinador nacional o centros de coordinación para el control del tabaco; y

b) adoptará y aplicará medidas legislativas, ejecutivas, administrativas y/o otras medidas eficaces y cooperará, según proceda, con otras Partes en la elaboración de políticas apropiadas para prevenir y reducir el consumo de tabaco, la adicción a la nicotina y la exposición al humo de tabaco.

3. A la hora de establecer y aplicar sus políticas de salud pública relativas al control del tabaco, las Partes actuarán de una manera que proteja dichas políticas contra los intereses comerciales y otros intereses creados de la industria tabacalera, de conformidad con la legislación nacional.

4. Las Partes cooperarán en la formulación de propuestas sobre medidas, procedimientos y directrices para la aplicación del Convenio y de los protocolos a los que se hayan adherido.

5. Las Partes cooperarán según proceda con las organizaciones intergubernamentales internacionales y regionales y otros órganos competentes para alcanzar los objetivos del Convenio y de los protocolos a los que se hayan adherido.

6. Las Partes, con arreglo a los medios y recursos de que dispongan, cooperarán a fin de obtener recursos financieros para aplicar efectivamente el Convenio mediante mecanismos de financiamiento bilaterales y multilaterales.

\section{PARTE III: MEDIDAS RELACIONADAS CON LA REDUCCIÓN DE LA DEMANDA DE TABACO}

Artículo 6

\section{Medidas relacionadas con los precios e impuestos para reducir la demanda de tabaco}

1. Las Partes reconocen que las medidas relacionadas con los precios e impuestos son un medio eficaz e importante para que diversos sectores de la población, en particular los jóvenes, reduzcan su consumo de tabaco. 
2. Sin perjuicio del derecho soberano de las Partes a decidir y establecer su propia política tributaria, cada Parte tendrá en cuenta sus objetivos nacionales de salud en lo referente al control del tabaco y adoptará o mantendrá, según proceda, medidas como las siguientes:

a) aplicar a los productos de tabaco políticas tributarias y, si corresponde, políticas de precios para contribuir al logro de los objetivos de salud tendentes a reducir el consumo de tabaco; $y$

b) prohibir o restringir, según proceda, la venta y/o la importación de productos de tabaco libres de impuestos y libres de derechos de aduana por los viajeros internacionales.

3. De conformidad con el artículo 21, en sus informes periódicos a la Conferencia de las Partes, éstas comunicarán las tasas impositivas aplicadas a los productos de tabaco y las tendencias del consumo de dichos productos.

\section{Artículo 7}

\section{Medidas no relacionadas con los precios para reducir la demanda de tabaco}

Las Partes reconocen que las medidas integrales no relacionadas con los precios son un medio eficaz e importante para reducir el consumo de tabaco. Cada Parte adoptará y aplicará medidas legislativas, ejecutivas, administrativas u otras medidas eficaces que sean necesarias para el cumplimiento de sus obligaciones dimanantes de los artículos 8 a 13 y cooperará con las demás Partes según proceda, directamente o por intermedio de los organismos internacionales competentes, con miras a su cumplimiento. La Conferencia de las Partes propondrá directrices apropiadas para la aplicación de lo dispuesto en esos artículos.

\section{Artículo 8 \\ Protección contra la exposición al humo de tabaco}

1. Las Partes reconocen que la ciencia ha demostrado de manera inequívoca que la exposición al humo de tabaco es causa de mortalidad, morbilidad y discapacidad.

2. Cada Parte adoptará y aplicará, en áreas de la jurisdicción nacional existente y conforme determine la legislación nacional, medidas legislativas, ejecutivas, administrativas y/u otras medidas eficaces de protección contra la exposición al humo de tabaco en lugares de trabajo interiores, medios de transporte público, lugares públicos cerrados y, según proceda, otros lugares públicos, y promoverá activamente la adopción y aplicación de esas medidas en otros niveles jurisdiccionales.

\section{Artículo 9 \\ Reglamentación del contenido de los productos de tabaco}

La Conferencia de las Partes, en consulta con los órganos internacionales competentes, propondrá directrices sobre el análisis y la medición del contenido y las emisiones de los productos de tabaco y sobre la reglamentación de esos contenidos y emisiones. Cada Parte adoptará y aplicará medidas legislativas, ejecutivas y administrativas u otras medidas eficaces aprobadas por las autoridades nacionales competentes para que se lleven a la práctica dichos análisis y mediciones y esa reglamentación.

\section{Artículo 10}

Reglamentación de la divulgación de información sobre los productos de tabaco

Cada Parte adoptará y aplicará, de conformidad con su legislación nacional,

Rev Esp Salud Pública 2003, Vol. 77, N. ${ }^{\circ} 4$ 
medidas legislativas, ejecutivas, administrativas u otras medidas eficaces para exigir que los fabricantes e importadores de productos de tabaco revelen a las autoridades gubernamentales la información relativa al contenido y las emisiones de los productos de tabaco. Cada Parte adoptará y aplicará asimismo medidas eficaces para que se revele al público la información relativa a los componentes tóxicos de los productos de tabaco y las emisiones que éstos pueden producir.

\section{Artículo 11 \\ Empaquetado y etiquetado de los productos de tabaco}

1. Cada Parte, dentro de un periodo de tres años a partir de la entrada en vigor del Convenio para esa Parte, adoptará y aplicará, de conformidad con su legislación nacional, medidas eficaces para conseguir lo siguiente:

a) que en los paquetes y etiquetas de los productos de tabaco no se promocione un producto de tabaco de manera falsa, equívoca o engañosa o que pueda inducir a error con respecto a sus características, efectos para la salud, riesgos o emisiones, y no se empleen términos, elementos descriptivos, marcas de fábrica o de comercio, signos figurativos o de otra clase que tengan el efecto directo o indirecto de crear la falsa impresión de que un determinado producto de tabaco es menos nocivo que otros, por ejemplo expresiones tales como «con bajo contenido de alquitrán», «ligeros», «ultra ligeros» o «suaves»; y

b) que en todos los paquetes y envases de productos de tabaco y en todo empaquetado y etiquetado externos de los mismos figuren también advertencias sanitarias que describan los efectos nocivos del consumo de tabaco, y que puedan incluirse otros mensajes apro- piados. Dichas advertencias y mensajes:

i) serán aprobados por las autoridades nacionales competentes;

ii) serán rotativos;

iii) serán grandes, claros, visibles y legibles;

iv) deberían ocupar el $50 \%$ o más de las superficies principales expuestas y en ningún caso menos del $30 \%$ de las superficies principales expuestas;

v) podrán consistir en imágenes o pictogramas, o incluirlos.

2. Todos los paquetes y envases de productos de tabaco y todo empaquetado y etiquetado externos de los mismos, además de las advertencias especificadas en el párrafo 1(b) de este artículo, contendrán información sobre los componentes pertinentes de los productos de tabaco y de sus emisiones de conformidad con lo definido por las autoridades nacionales.

3. Cada Parte exigirá que las advertencias y la información textual especificadas en los párrafos 1(b) y 2 del presente artículo figuren en todos los paquetes y envases de productos de tabaco y en todo empaquetado y etiquetado externos de los mismos en su idioma o idiomas principales.

4. A efectos del presente artículo, la expresión «empaquetado y etiquetado externos» en relación con los productos de tabaco se aplica a todo envasado y etiquetado utilizados en la venta al por menor del producto.

\section{Artículo 12}

\section{Educación, comunicación, formación y concientización del público}

Cada Parte promoverá y fortalecerá la concientización del público acerca de las 
cuestiones relativas al control del tabaco utilizando de forma apropiada todos los instrumentos de comunicación disponibles.

Con ese fin, cada Parte adoptará y aplicará medidas legislativas, ejecutivas, administrativas $\mathrm{u}$ otras medidas eficaces para promover lo siguiente:

a) un amplio acceso a programas integrales y eficaces de educación y concientización del público sobre los riesgos que acarrean para la salud el consumo de tabaco y la exposición al humo de tabaco, incluidas sus propiedades adictivas;

b) la concientización del público acerca de los riesgos que acarrean para la salud el consumo de tabaco y la exposición al humo de tabaco, así como de los beneficios que reportan el abandono de dicho consumo y los modos de vida sin tabaco, conforme a lo especificado en el párrafo 2 del artículo 14;

c) el acceso del público, de conformidad con la legislación nacional, a una amplia variedad de información sobre la industria tabacalera que revista interés para el objetivo del presente Convenio;

d programas eficaces y apropiados de formación o sensibilización y concientización sobre el control del tabaco dirigidos a personas tales como profesionales de la salud, trabajadores de la comunidad, asistentes sociales, profesionales de la comunicación, educadores, responsables de las políticas, administradores y otras personas interesadas;

e) la concientización y la participación de organismos públicos y privados y organizaciones no gubernamentales no asociadas a la industria tabacalera en la elaboración y aplicación de programas y estrategias intersectoriales de control del tabaco; y f) el conocimiento público y el acceso a la información sobre las consecuencias sanitarias, económicas y ambientales adversas de la producción y el consumo de tabaco.

\section{Artículo 13}

\section{Publicidad, promoción y patrocinio del tabaco}

1. Las Partes reconocen que una prohibición total de la publicidad, la promoción y el patrocinio reduciría el consumo de productos de tabaco.

2. Cada Parte, de conformidad con su constitución o sus principios constitucionales, procederá a una prohibición total de toda forma de publicidad, promoción y patrocinio del tabaco. Dicha prohibición comprenderá, de acuerdo con el entorno jurídico y los medios técnicos de que disponga la Parte en cuestión, una prohibición total de la publicidad, la promoción y el patrocinio transfronterizos originados en su territorio. A este respecto, cada Parte, dentro de un plazo de cinco años a partir de la entrada en vigor del Convenio para la Parte en cuestión, adoptará medidas legislativas, ejecutivas, administrativas u otras medidas apropiadas e informará en consecuencia de conformidad con el artículo 21 .

3. La Parte que no esté en condiciones de proceder a una prohibición total debido a las disposiciones de su constitución o sus principios constitucionales aplicará restricciones a toda forma de publicidad, promoción y patrocinio del tabaco. Dichas restricciones comprenderán, de acuerdo con el entorno jurídico y los medios técnicos de que disponga la Parte en cuestión, la restricción o una prohibición total de la publicidad, la promoción y el patrocinio originados en su territorio que tengan efectos transfronterizos. A este respecto, cada Parte adoptará medidas legislativas, ejecutivas, administrativas $\mathrm{u}$ 
otras medidas apropiadas e informará en consecuencia de conformidad con el artículo 21.

4. Como mínimo, y de conformidad con su constitución o sus principios constitucionales, cada Parte:

a) prohibirá toda forma de publicidad, promoción y patrocinio del tabaco que promueva un producto de tabaco por cualquier medio que sea falso, equívoco o engañoso en alguna otra forma o que pueda crear una impresión errónea con respecto a sus características, efectos para la salud, riesgos o emisiones;

b) exigirá que toda publicidad de tabaco y, según proceda, su promoción y patrocinio, vaya acompañada de una advertencia o mensaje sanitario o de otro tipo pertinente;

c) restringirá el uso de incentivos directos o indirectos que fomenten la compra de productos de tabaco por parte de la población;

d) exigirá, si no ha adoptado una prohibición total, que se revelen a las autoridades gubernamentales competentes los gastos efectuados por la industria del tabaco en actividades de publicidad, promoción y patrocinio aún no prohibidas. Dichas autoridades podrán decidir que esas cifras, a reserva de lo dispuesto en la legislación nacional, se pongan a disposición del público y de la Conferencia de las Partes de conformidad con el artículo 21;

e) procederá dentro de un plazo de cinco años a una prohibición total o, si la Parte no puede imponer una prohibición total debido a su constitución o sus principios constitucionales, a la restricción de la publicidad, la promoción y el patrocinio por radio, televisión, medios impresos y, según proceda, otros medios, como Internet; y f) prohibirá o, si la Parte no puede imponer la prohibición debido a su constitución o sus principios constitucionales, restringirá el patrocinio de acontecimientos y actividades internacionales o de participantes en las mismas por parte de empresas tabacaleras.

5. Se alienta a las Partes a que pongan en práctica medidas que vayan más allá de las obligaciones establecidas en el párrafo 4.

6. Las Partes cooperarán en el desarrollo de tecnologías y de otros medios necesarios para facilitar la eliminación de la publicidad transfronteriza.

7. Las Partes que hayan prohibido determinadas formas de publicidad, promoción y patrocinio del tabaco tendrán el derecho soberano de prohibir las formas de publicidad, promoción y patrocinio transfronterizos de productos de tabaco que penetren en su territorio, así como de imponerles las mismas sanciones previstas para la publicidad, la promoción y el patrocinio que se originen en su territorio, de conformidad con la legislación nacional. El presente párrafo no respalda ni aprueba ninguna sanción en particular.

8. Las Partes considerarán la elaboración de un protocolo en el cual se establezcan medidas apropiadas que requieran colaboración internacional para prohibir completamente la publicidad, la promoción y el patrocinio transfronterizos.

\section{Artículo 14}

\section{Medidas de reducción de la demanda relativas a la dependencia y al abandono del tabaco}

1. Cada Parte elaborará y difundirá directrices apropiadas, completas e integradas, basadas en pruebas científicas y en las mejores prácticas, teniendo presentes las circunstancias y prioridades nacionales, y adoptará 
medidas eficaces para promover el abandono del consumo de tabaco y el tratamiento adecuado de la dependencia del tabaco.

2. Con ese fin, cada Parte procurará lo siguiente:

a) idear y aplicar programas eficaces de promoción del abandono del consumo de tabaco en lugares tales como instituciones docentes, unidades de salud, lugares de trabajo y entornos deportivos;

b) incorporar el diagnóstico y el tratamiento de la dependencia del tabaco y servicios de asesoramiento sobre el abandono del tabaco en programas, planes y estrategias nacionales de salud y educación, con la participación de profesionales de la salud, trabajadores comunitarios y asistentes sociales, según proceda;

c) establecer en los centros de salud y de rehabilitación programas de diagnóstico, asesoramiento, prevención y tratamiento de la dependencia del tabaco; y d) colaborar con otras Partes para facilitar la accesibilidad y asequibilidad de los tratamientos de la dependencia del tabaco, incluidos productos farmacéuticos, de conformidad con el artículo 22.

Dichos productos y sus componentes pueden ser medicamentos, productos usados para administrar medicamentos y medios diagnósticos cuando proceda.

\section{PARTE IV: MEDIDAS RELACIONADAS CON LA REDUCCIÓN DE LA OFERTA DE TABACO}

\section{Artículo 15}

\section{Comercio ilícito de productos de tabaco 1}

1. Las Partes reconocen que la eliminación de todas las formas de comercio ilícito de productos de tabaco, como el contrabando, la fabricación ilícita y la falsificación, y la elaboración y aplicación a este respecto de una legislación nacional y de acuerdos subregionales, regionales y mundiales son componentes esenciales del control del tabaco.

2. Cada Parte adoptará y aplicará medidas legislativas, ejecutivas, administrativas $\mathrm{u}$ otras medidas eficaces para que todos los paquetes o envases de productos de tabaco y todo empaquetado externo de dichos productos lleven una indicación que ayude a las Partes a determinar el origen de los productos de tabaco y, de conformidad con la legislación nacional y los acuerdos bilaterales o multilaterales pertinentes, ayude a las Partes a determinar el punto de desviación y a vigilar, documentar y controlar el movimiento de los productos de tabaco y su situación legal. Además, cada Parte:

a) exigirá que todos los paquetes y envases de productos de tabaco para uso al detalle y al por mayor que se vendan en su mercado interno lleven la declaración: «Venta autorizada únicamente en (insertar el nombre del país o de la unidad subnacional, regional o federal)», o lleven cualquier otra indicación útil en la que figure el destino final o que ayude a las autoridades a determinar si está legalmente autorizada la venta del producto en el mercado interno; y

b) examinará, según proceda, la posibilidad de establecer un régimen práctico de seguimiento y localización que dé más garantías al sistema de distribución y ayude en la investigación del comercio ilícito.

3. Cada Parte exigirá que la información o las indicaciones que ha de llevar el empaquetado según el párrafo 2 del presente artículo figuren en forma legible y/o en el idioma o los idiomas principales del país. 
4. Con miras a eliminar el comercio ilícito de productos de tabaco, cada Parte:

a) hará un seguimiento del comercio transfronterizo de productos de tabaco, incluido el comercio ilícito, reunirá datos sobre el particular e intercambiará información entre autoridades aduaneras, tributarias y otras autoridades, según proceda y de conformidad con la legislación nacional y los acuerdos bilaterales o multilaterales pertinentes aplicables;

1 Durante todo el proceso de prenegociación y negociación del Convenio Marco se ha debatido extensamente la posibilidad de adoptar pronto un protocolo sobre el comercio ilícito de productos de tabaco. El ONI podría iniciar la negociación de dicho protocolo inmediatamente después de la adopción del Convenio Marco, o podría hacerlo la Conferencia de las Partes en una etapa posterior. b) promulgará o fortalecerá legislación, con sanciones y recursos apropiados, contra el comercio ilícito de productos de tabaco, incluidos los cigarrillos falsificados y de contrabando;

c) adoptará medidas apropiadas para garantizar que todos los cigarrillos y productos de tabaco falsificados y de contrabando y todo equipo de fabricación de éstos que se hayan decomisado se destruyan aplicando métodos inocuos para el medio ambiente cuando sea factible, o se eliminen de conformidad con la legislación nacional;

d) adoptará y aplicará medidas para vigilar, documentar y controlar el almacenamiento y la distribución de productos de tabaco que se encuentren o se desplacen en su jurisdicción en régimen de suspensión de impuestos o derechos; y e) adoptará las medidas que procedan para posibilitar la incautación de los beneficios derivados del comercio ilícito de productos de tabaco.

5. La información recogida con arreglo a lo dispuesto en los párrafos 4(a) y 4(d) del presente artículo será transmitida, según proceda, en forma global por las Partes en sus informes periódicos a la Conferencia de las Partes, de conformidad con el artículo 21.

6. Las Partes promoverán, según proceda y conforme a la legislación nacional, la cooperación entre los organismos nacionales, así como entre las organizaciones intergubernamentales regionales e internacionales pertinentes, en lo referente a investigaciones, enjuiciamientos y procedimientos judiciales con miras a eliminar el comercio ilícito de productos de tabaco. Se prestará especial atención a la cooperación a nivel regional y subregional para combatir el comercio ilícito de productos de tabaco.

7. Cada Parte procurará adoptar y aplicar medidas adicionales, como la expedición de licencias, cuando proceda, para controlar o reglamentar la producción y distribución de los productos de tabaco a fin de prevenir el comercio ilícito.

\section{Artículo 16}

\section{Ventas a menores y por menores}

1. Cada Parte adoptará y aplicará en el nivel gubernamental apropiado medidas legislativas, ejecutivas, administrativas u otras medidas eficaces para prohibir la venta de productos de tabaco a los menores de la edad que determine la legislación interna, la legislación nacional o a los menores de 18 años. Dichas medidas podrán consistir en lo siguiente:

a) exigir que todos los vendedores de productos de tabaco indiquen, en un 
anuncio claro y destacado situado en el interior de su local, la prohibición de la venta de productos de tabaco a los menores y, en caso de duda, soliciten que cada comprador de tabaco demuestre que ha alcanzado la mayoría de edad;

b) prohibir que los productos de tabaco en venta estén directamente accesibles, como en los estantes de los almacenes;

c) prohibir la fabricación y venta de dulces, refrigerios, juguetes y otros objetos que tengan forma de productos de tabaco y puedan resultar atractivos para los menores; y d) garantizar que las máquinas expendedoras de tabaco bajo su jurisdicción no sean accesibles a los menores y no promuevan la venta de productos de tabaco a los menores.

2. Cada Parte prohibirá o promoverá la prohibición de la distribución gratuita de productos de tabaco al público y especialmente a los menores.

3. Cada Parte procurará prohibir la venta de cigarrillos sueltos o en paquetes pequeños que vuelvan más asequibles esos productos a los menores de edad.

4. Las Partes reconocen que, para que sean más eficaces, las medidas encaminadas a impedir la venta de productos de tabaco a los menores de edad deben aplicarse, cuando proceda, conjuntamente con otras disposiciones previstas en el presente Convenio.

5.A la hora de firmar, ratificar, aceptar o aprobar el presente Convenio o de adherirse al mismo, o en cualquier otro momento posterior, toda Parte podrá indicar mediante una declaración escrita que se compromete a prohibir la introducción de máquinas expendedoras de tabaco dentro de su jurisdicción o, según proceda, a prohibir completamente las máquinas expendedoras de tabaco. El Depositario distribuirá a todas las Partes en el Convenio las declaraciones que se formulen de conformidad con el presente artículo.

6. Cada Parte adoptará y aplicará medidas legislativas, ejecutivas, administrativas u otras medidas eficaces, con inclusión de sanciones contra los vendedores y distribuidores, para asegurar el cumplimiento de las obligaciones establecidas en los párrafos $1 \mathrm{a}$ 5 del presente artículo.

7. Cada Parte debería adoptar y aplicar, según proceda, medidas legislativas, ejecutivas, administrativas u otras medidas eficaces para prohibir la venta de productos de tabaco por personas de una edad menor a la establecida en la legislación interna, la legislación nacional o por menores de 18 años.

\section{Artículo 17}

\section{Apoyo a actividades alternativas económicamente viables}

Las Partes, en cooperación entre sí y con las organizaciones intergubernamentales internacionales y regionales competentes, promoverán según proceda alternativas económicamente viables para los trabajadores, los cultivadores y eventualmente, los pequeños vendedores de tabaco.

\section{PARTE V: PROTECCIÓN DEL MEDIO AMBIENTE}

\section{Artículo 18}

\section{Protección del medio ambiente y de la salud de las personas}

En cumplimiento de sus obligaciones establecidas en el presente Convenio, las Partes acuerdan prestar debida atención a la protección ambiental y a la salud de las personas en relación con el medio ambiente por lo que respecta al cultivo de tabaco y a la 
fabricación de productos de tabaco, en sus respectivos territorios.

\section{PARTE VI: CUESTIONES RELACIONADAS CON LA RESPONSABILIDAD}

\section{Artículo 19}

\section{Responsabilidad}

1. Con fines de control del tabaco, las Partes considerarán la adopción de medidas legislativas o la promoción de sus leyes vigentes, cuando sea necesario, para ocuparse de la responsabilidad penal y civil, inclusive la compensación cuando proceda.

2. Las Partes cooperarán entre sí en el intercambio de información por intermedio de la Conferencia de las Partes, de conformidad con el artículo 21, a saber:

a) información, de conformidad con el párrafo 3(a) del artículo 20, sobre los efectos en la salud del consumo de productos de tabaco y la exposición al humo de tabaco; y

b) información sobre la legislación y los reglamentos vigentes y sobre la jurisprudencia pertinente.

3. Las Partes, según proceda y según hayan acordado entre sí, dentro de los límites de la legislación, las políticas y las prácticas jurídicas nacionales, así como de los tratados vigentes aplicables, se prestarán recíprocamente ayuda en los procedimientos judiciales relativos a la responsabilidad civil y penal, de forma coherente con el presente Convenio.

4. El Convenio no afectará en absoluto a los derechos de acceso de las Partes a los tribunales de las otras Partes, donde existan esos derechos, ni los limitará en modo alguno.
5 La Conferencia de las Partes podrá considerar, si es posible, en una etapa temprana, teniendo en cuenta los trabajos en curso en foros internacionales pertinentes, cuestiones relacionadas con la responsabilidad, incluidos enfoques internacionales apropiados de dichas cuestiones y medios idóneos para apoyar a las Partes, cuando así lo soliciten, en sus actividades legislativas o de otra índole de conformidad con el presente artículo.

\section{PARTE VII: COOPERACIÓN TÉCNICA Y CIENTÍFICA Y COMUNICACIÓN DE INFORMACIÓN}

\section{Artículo 20}

\section{Investigación, vigilancia e intercambio de información}

1. Las Partes se comprometen a elaborar y promover investigaciones nacionales y a coordinar programas de investigación regionales e internacionales sobre control del tabaco. Con ese fin, cada Parte:

a) iniciará, directamente o por conducto de organizaciones intergubernamentales internacionales y regionales y de otros órganos competentes, investigaciones y evaluaciones científicas, cooperará en ellas y promoverá y alentará así investigaciones que aborden los factores determinantes y las consecuencias del consumo de tabaco y de la exposición al humo de tabaco e investigaciones tendentes a identificar cultivos alternativos; $y$

b) promoverá y fortalecerá, con el respaldo de organizaciones intergubernamentales internacionales y regionales y de otros órganos competentes, la capacitación y el apoyo destinados a todos los que se ocupen de actividades de control del tabaco, incluidas la investigación, la ejecución y la evaluación. 
2. Las Partes establecerán, según proceda, programas de vigilancia nacional, regional y mundial de la magnitud, las pautas, los determinantes y las consecuencias del consumo de tabaco y de la exposición al humo de tabaco. Con ese fin, las Partes integrarán programas de vigilancia del tabaco en los programas nacionales, regionales y mundiales de vigilancia sanitaria para que los datos se puedan cotejar y analizar a nivel regional e internacional, según proceda.

3. Las Partes reconocen la importancia de la asistencia financiera y técnica de las organizaciones intergubernamentales internacionales y regionales y de otros órganos. Cada Parte procurará:

a) establecer progresivamente un sistema nacional de vigilancia epidemiológica del consumo de tabaco y de los indicadores sociales, económicos y de salud conexos;

b) cooperar con organizaciones intergubernamentales internacionales y regionales y con otros órganos competentes, incluidos organismos gubernamentales y no gubernamentales, en la vigilancia regional y mundial del tabaco y en el intercambio de información sobre los indicadores especificados en el párrafo 3(a) del presente artículo; y

c) cooperar con la Organización Mundial de la Salud en la elaboración de directrices o procedimientos de carácter general para definir la recopilación, el análisis y la difusión de datos de vigilancia relacionados con el tabaco.

4. Las Partes, con arreglo a la legislación nacional, promoverán y facilitarán el intercambio de información científica, técnica, socioeconómica, comercial y jurídica de dominio público, así como de información sobre las prácticas de la industria tabacalera y sobre el cultivo de tabaco, que sea pertinente para este Convenio, y al hacerlo tendrán en cuenta y abordarán las necesidades especiales de las Partes que sean países en desarrollo o tengan economías en transición. Cada Parte procurará:

a) establecer progresivamente y mantener una base de datos actualizada sobre las leyes y reglamentos de control del tabaco y, según proceda, información sobre su aplicación, así como sobre la jurisprudencia pertinente, y cooperar en la elaboración de programas de control del tabaco a nivel regional y mundial;

b) compilar progresivamente y actualizar datos procedentes de los programas nacionales de vigilancia, de conformidad con el párrafo 3(a) del presente artículo; y

c) cooperar con organizaciones internacionales competentes para establecer progresivamente y mantener un sistema mundial con objeto de reunir regularmente y difundir información sobre la producción y manufactura del tabaco y sobre las actividades de la industria tabacalera que tengan repercusiones para este Convenio o para las actividades nacionales de control del tabaco.

5. Las Partes deberán cooperar en las organizaciones intergubernamentales regionales e internacionales y en las instituciones financieras y de desarrollo a que pertenezcan, a fin de fomentar y alentar el suministro de recursos técnicos y financieros a la Secretaría del Convenio para ayudar a las Partes que sean países en desarrollo o tengan economías en transición a cumplir con sus compromisos de vigilancia, investigación e intercambio de información.

\section{Artículo 21}

\section{Presentación de informes e intercambio de información}

1. Cada Parte presentará a la Conferencia de las Partes, por conducto de la Secretaría, 
informes periódicos sobre su aplicación del Convenio, que deberían incluir lo siguiente:

a) información sobre las medidas legislativas, ejecutivas, administrativas o de otra índole adoptadas para aplicar el Convenio;

b) información, según proceda, sobre toda limitación u obstáculo surgido en la aplicación del Convenio y sobre las medidas adoptadas para superar esos obstáculos;

c) información, según proceda, sobre la ayuda financiera o técnica suministrada o recibida para actividades de control del tabaco;

d) información sobre la vigilancia y la investigación especificadas en el artículo 20; y

e) información conforme a lo especificado en los artículos 6.3, 13.2, 13.3, 13.4(d), 15.5 y 19.2 .

2. La frecuencia y la forma de presentación de esos informes de todas las Partes serán determinadas por la Conferencia de las Partes. Cada Parte elaborará su informe inicial en el término de los dos años siguientes a la entrada en vigor de este Convenio para dicha Parte.

3. La Conferencia de las Partes, de conformidad con los artículos 22 y 26, considerará mecanismos para ayudar a las Partes que sean países en desarrollo o tengan economías en transición, a petición de esas Partes, a cumplir con sus obligaciones estipuladas en este artículo.

4. La presentación de informes y el intercambio de información previstos en el presente Convenio estarán sujetos a la legislación nacional relativa a la confidencialidad y la privacidad. Las Partes protegerán, según decidan de común acuerdo, toda información confidencial que se intercambie.

\section{Artículo 22}

Cooperación científica, técnica y jurídica y prestación de asesoramiento especializado

1. Las Partes cooperarán directamente o por conducto de los organismos internacionales competentes a fin de fortalecer su capacidad para cumplir las obligaciones dimanantes de este Convenio, teniendo en cuenta las necesidades de las Partes que sean países en desarrollo o tengan economías en transición. Esa cooperación promoverá la transferencia de conocimientos técnicos, científicos y jurídicos especializados y de tecnología, según se haya decidido de común acuerdo, con objeto de establecer y fortalecer estrategias, planes y programas nacionales de control del tabaco encaminados, entre otras cosas, a lo siguiente:

a) facilitar el desarrollo, la transferencia y la adquisición de tecnología, conocimiento, aptitudes, capacidad y competencia técnica relacionados con el control del tabaco; b) prestar asesoramiento técnico, científico, jurídico y de otra índole a fin de establecer y fortalecer estrategias, planes y programas nacionales de control del tabaco, con miras a la aplicación del Convenio mediante, entre otras cosas, lo siguiente:

i) ayuda, cuando así se solicite, para crear una sólida base legislativa, así como programas técnicos, en particular programas de prevención del inicio del consumo de tabaco, promoción del abandono del tabaco y protección contra la exposición al humo de tabaco;

ii ayuda, según proceda, a los trabajadores del sector del tabaco para desarrollar de manera económicamente viable medios de subsistencia alternativos apropiados que sean económicamente y legalmente viables; 
iii) ayuda, según proceda, a los cultivadores de tabaco para llevar a efecto la transición de la producción agrícola hacia cultivos alternativos de manera económicamente viable;

c) respaldar programas de formación o sensibilización apropiados para el personal pertinente, según lo dispuesto en el artículo 12;

d) proporcionar, según proceda, el material, el equipo y los suministros necesarios, así como apoyo logístico, para las estrategias, planes y programas de control del tabaco;

e) determinar métodos de control del tabaco, incluido el tratamiento integral de la adicción a la nicotina; $y$

f) promover, según proceda, investigaciones encaminadas a mejorar la asequibilidad del tratamiento integral de la adicción a la nicotina.

2. La Conferencia de las Partes promoverá y facilitará la transferencia de conocimientos técnicos, científicos y jurídicos especializados y de tecnología con el apoyo financiero garantizado de conformidad con el artículo 26.

\section{PARTE VIII: ARREGLOS INSTITUCIONALES Y RECURSOS FINANCIEROS}

\section{Artículo 23}

\section{Conferencia de las Partes}

1. Por el presente se establece una Conferencia de las Partes. La primera reunión de la Conferencia de las Partes será convocada por la Organización Mundial de la Salud a más tardar un año después de la entrada en vigor de este Convenio. La Conferencia determinará en su primera reunión el lugar y las fechas de las reuniones subsiguientes que se celebrarán regularmente.
2. Se celebrarán reuniones extraordinarias de la Conferencia de las Partes en las ocasiones en que la Conferencia lo considere necesario, o cuando alguna de las Partes lo solicite por escrito, siempre que, dentro de los seis meses siguientes a la fecha en que la Secretaría del Convenio haya comunicado a las Partes la solicitud, ésta reciba el apoyo de al menos un tercio de las Partes.

3. La Conferencia de las Partes adoptará por consenso su Reglamento Interior en su primera reunión.

4. La Conferencia de las Partes adoptará por consenso sus normas de gestión financiera, que regirán también el financiamiento de cualquier órgano subsidiario que pueda establecer, así como las disposiciones financieras que regirán el funcionamiento de la Secretaría. En cada reunión ordinaria adoptará un presupuesto para el ejercicio financiero hasta la siguiente reunión ordinaria.

5. La Conferencia de las Partes examinará regularmente la aplicación del Convenio, adoptará las decisiones necesarias para promover su aplicación eficaz y podrá adoptar protocolos, anexos y enmiendas del Convenio de conformidad con lo dispuesto en los artículos 28, 29 y 33. Para ello:

a) promoverá y facilitará el intercambio de información de conformidad con los artículos 20 y 21;

b) promoverá y orientará el establecimiento y el perfeccionamiento periódico de metodologías comparables de investigación y acopio de datos, además de las previstas en el artículo 20, que sean pertinentes para la aplicación del Convenio;

c) promoverá, según proceda, el desarrollo, la aplicación y la evaluación de estrategias, planes, programas, políticas, legislación y otras medidas;

Rev Esp Salud Pública 2003, Vol. 77, N. ${ }^{\circ} 4$ 
d) considerará los informes que le presenten las Partes de conformidad con el artículo 21 y adoptará informes regulares sobre la aplicación del Convenio;

e) promoverá y facilitará la movilización de recursos financieros para la aplicación del Convenio de conformidad con el artículo 26;

f) establecerá los órganos subsidiarios necesarios para cumplir con el objetivo del Convenio;

g) recabará, cuando corresponda, los servicios, la cooperación y la información de las organizaciones y órganos del sistema de las Naciones Unidas y de otras organizaciones y órganos intergubernamentales y no gubernamentales internacionales y regionales competentes y pertinentes como medio para fortalecer la aplicación del Convenio; y

h) considerará otras medidas, según proceda, para alcanzar el objetivo del Convenio, teniendo presente la experiencia adquirida en su aplicación.

6. La Conferencia de las Partes establecerá los criterios para la participación de observadores en sus reuniones.

\section{Artículo 24}

\section{Secretaría}

1. La Conferencia de las Partes designará una secretaría permanente y adoptará disposiciones para su funcionamiento. La Conferencia de las Partes procurará hacer esto en su primera reunión.

2. Hasta que se haya designado y establecido una secretaría permanente, las funciones de secretaría de este Convenio estarán a cargo de la Organización Mundial de la Salud.

3. Las funciones de la Secretaría serán las siguientes: a) adoptar disposiciones para las reuniones de la Conferencia de las Partes y de cualquiera de sus órganos subsidiarios y prestarles los servicios necesarios;

b) transmitir los informes que haya recibido en virtud del Convenio;

c) prestar apoyo a las Partes, en particular a las que sean países en desarrollo o tengan economías en transición, cuando así lo soliciten, en la recopilación y transmisión de la información requerida de conformidad con las disposiciones del Convenio;

d) preparar informes sobre sus actividades en el marco de este Convenio, siguiendo las orientaciones de la Conferencia de las Partes, y someterlos a la Conferencia de las Partes;

e) asegurar, bajo la orientación de la Conferencia de las Partes, la coordinación necesaria con las organizaciones intergubernamentales internacionales y regionales y otros órganos competentes;

f) concertar, bajo la orientación de la Conferencia de las Partes, los arreglos administrativos y contractuales que sean necesarios para el ejercicio eficaz de sus funciones; y

g) desempeñar otras funciones de secretaría especificadas en el Convenio y en cualquiera de sus protocolos, y las que determine la Conferencia de las Partes.

\section{Artículo 25}

\section{Relaciones entre la Conferencia de las Partes y las organizaciones intergubernamentales}

Para prestar cooperación técnica y financiera a fin de alcanzar el objetivo de este 
Convenio, la Conferencia de las Partes podrá solicitar la cooperación de organizaciones intergubernamentales internacionales y regionales competentes, incluidas las instituciones de financiamiento y desarrollo.

\section{Artículo 26}

\section{Recursos financieros}

1. Las Partes reconocen la importancia que tienen los recursos financieros para alcanzar el objetivo del presente Convenio.

2. Cada Parte prestará apoyo financiero para sus actividades nacionales destinadas a alcanzar el objetivo del Convenio, de conformidad con sus planes, prioridades y programas nacionales.

3. Las Partes promoverán, según proceda, la utilización de vías bilaterales, regionales, subregionales y otros canales multilaterales para financiar la elaboración y el fortalecimiento de programas multisectoriales integrales de control del tabaco de las Partes que sean países en desarrollo y de las que tengan economías en transición. Por consiguiente, deben abordarse y apoyarse, en el contexto de estrategias nacionales de desarrollo sostenible, alternativas económicamente viables a la producción de tabaco, entre ellas la diversificación de cultivos.

4. Las Partes representadas en las organizaciones intergubernamentales regionales e internacionales y las instituciones financieras y de desarrollo pertinentes alentarán a estas entidades a que faciliten asistencia financiera a las Partes que sean países en desarrollo y a las que tengan economías en transición para ayudarlas a cumplir sus obligaciones en virtud del presente Convenio, sin limitar los derechos de participación en esas organizaciones.

5. Las Partes acuerdan lo siguiente:

a) a fin de ayudar a las Partes a cumplir sus obligaciones en virtud del Convenio, se deben movilizar y utilizar en beneficio de todas las Partes, en especial de los países en desarrollo y los países con economías en transición, todos los recursos pertinentes, existentes o potenciales, ya sean financieros, técnicos o de otra índole, tanto públicos como privados, disponibles para actividades de control del tabaco;

b) la Secretaría informará a las Partes que sean países en desarrollo y a las que tengan economías en transición, previa solicitud, sobre fuentes de financiamiento disponibles para facilitar el cumplimiento de sus obligaciones en virtud del Convenio;

c) la Conferencia de las Partes en su primera reunión examinará las fuentes y mecanismos existentes y potenciales de asistencia sobre la base de un estudio realizado por la Secretaría y de otra información pertinente, y considerará su adecuación; y

d) los resultados de este examen serán tenidos en cuenta por la Conferencia de las Partes a la hora de determinar la necesidad de mejorar los mecanismos existentes o establecer un fondo mundial voluntario u otros mecanismos financieros apropiados para canalizar recursos financieros adicionales, según sea necesario, a las Partes que sean países en desarrollo y a las que tengan economías en transición para ayudarlas a alcanzar los objetivos del Convenio.

\section{PARTE IX: SOLUCIÓN DE CONTROVERSIAS}

\section{Artículo 27}

\section{Solución de controversias}

1. Si surge una controversia entre dos o más Partes respecto de la interpretación o la

Rev Esp Salud Pública 2003, Vol. 77, N. ${ }^{\circ} 4$ 
aplicación del presente Convenio, esas Partes procurarán resolver la controversia por vía diplomática mediante negociación o cualquier otro medio pacífico de su elección, por ejemplo buenos oficios, mediación o conciliación. El hecho de que no se llegue a un acuerdo mediante buenos oficios, mediación o conciliación no eximirá a las Partes en la controversia de la responsabilidad de seguir tratando de resolverla.

2. Al ratificar, aceptar, aprobar o confirmar oficialmente el Convenio, al adherirse a él, o en cualquier momento después de ello, un Estado u organización de integración económica regional podrá declarar por escrito al Depositario que, en caso de controversia no resuelta de conformidad con el párrafo 1 del presente artículo, acepta como obligatorio un arbitraje especial de acuerdo con los procedimientos que adopte por consenso la Conferencia de las Partes.

3. Las disposiciones del presente artículo se aplicarán a todos los protocolos y a las Partes en dichos protocolos, a menos que en ellos se disponga otra cosa.

\section{PARTE X: DESARROLLO DEL CONVENIO}

\section{Artículo 28}

\section{Enmiendas del presente Convenio}

1. Cualquiera de las Partes podrá proponer enmiendas del presente Convenio. Dichas enmiendas serán examinadas por la Conferencia de las Partes.

2. Las enmiendas del Convenio serán adoptadas por la Conferencia de las Partes. La Secretaría comunicará a las Partes el texto del proyecto de enmienda al menos seis meses antes de la reunión en la que se proponga su adopción. La Secretaría comunicará asimismo los proyectos de enmienda a los signatarios del Convenio y, a título informativo, al Depositario.
3. Las Partes harán todo lo posible por llegar a un acuerdo por consenso sobre cualquier propuesta de enmienda del Convenio. Si se agotan todas las posibilidades de llegar a un acuerdo por consenso, como último recurso la enmienda será adoptada por una mayoría de tres cuartos de las Partes presentes y votantes en la reunión. A los efectos del presente artículo, por «Partes presentes y votantes» se entiende las Partes presentes que emitan un voto a favor o en contra. La Secretaría comunicará toda enmienda adoptada al Depositario, y éste la hará llegar a todas las Partes para su aceptación.

4. Los instrumentos de aceptación de las enmiendas se entregarán al Depositario. Las enmiendas adoptadas de conformidad con el párrafo 3 del presente artículo entrarán en vigor, para las Partes que las hayan aceptado, al nonagésimo día contado desde la fecha en que el Depositario haya recibido instrumentos de aceptación de por lo menos dos tercios de las Partes en el Convenio.

5. Las enmiendas entrarán en vigor para las demás Partes al nonagésimo día contado desde la fecha en que se haya entregado al Depositario el instrumento de aceptación de las enmiendas en cuestión.

\section{Artículo 29}

\section{Adopción y enmienda de los anexos del presente Convenio}

1. Los anexos y enmiendas del presente Convenio se propondrán, se adoptarán y entrarán en vigor de conformidad con el procedimiento establecido en el artículo 28.

2. Los anexos del Convenio formarán parte integrante de éste y, salvo que se disponga expresamente otra cosa, toda referencia al Convenio constituirá al mismo tiempo una referencia a sus anexos.

3. En los anexos sólo se incluirán listas, formularios y otros materiales descriptivos 
relacionados con cuestiones de procedimiento y aspectos científicos, técnicos o administrativos.

\section{PARTE XI: DISPOSICIONES FINALES}

\section{Artículo 30}

\section{Reservas}

No podrán formularse reservas a este Convenio.

\section{Artículo 31 \\ Denuncia}

1. En cualquier momento después de un plazo de dos años a partir de la fecha de entrada en vigor del Convenio para una Parte, esa Parte podrá denunciar el Convenio, previa notificación por escrito al Depositario.

2. La denuncia surtirá efecto al cabo de un año contado desde la fecha en que el Depositario haya recibido la notificación correspondiente o, posteriormente, en la fecha que se indique en dicha notificación.

3. Se considerará que la Parte que denuncia el Convenio denuncia asimismo todo protocolo en que sea Parte.

\section{Artículo 32}

\section{Derecho de voto}

1. Salvo lo dispuesto en el párrafo 2 del presente artículo, cada Parte en el Convenio tendrá un voto.

2. Las organizaciones de integración económica regional, en los asuntos de su competencia, ejercerán su derecho de voto con un número de votos igual al número de sus Estados Miembros que sean Partes en el Convenio. Esas organizaciones no ejercerán su derecho de voto si cualquiera de sus Estados Miembros ejerce el suyo, y viceversa.

\section{Artículo 33 \\ Protocolos}

1. Cualquier Parte podrá proponer protocolos. Dichas propuestas serán examinadas por la Conferencia de las Partes.

2. La Conferencia de las Partes podrá adoptar protocolos del presente Convenio. $\mathrm{Al}$ adoptar tales protocolos deberá hacerse todo lo posible para llegar a un consenso. Si se agotan todas las posibilidades de llegar a un acuerdo por consenso, como último recurso el protocolo será adoptado por una mayoría de tres cuartos de las Partes presentes y votantes en la reunión. A los efectos del presente artículo, por «Partes presentes y votantes» se entiende las Partes presentes que emitan un voto a favor o en contra.

3. El texto de todo protocolo propuesto será comunicado a las Partes por la Secretaría al menos seis meses antes de la reunión en la cual se vaya a proponer para su adopción.

4. Sólo las Partes en el Convenio podrán ser Partes en un protocolo del Convenio.

5. Cualquier protocolo del Convenio sólo será vinculante para las Partes en el protocolo en cuestión. Sólo las Partes en un protocolo podrán adoptar decisiones sobre asuntos exclusivamente relacionados con el protocolo en cuestión.

6. Las condiciones para la entrada en vigor del protocolo serán las establecidas por ese instrumento.

\section{Artículo 34}

\section{Firma}

El presente Convenio estará abierto a la firma de todos los Miembros de la Organi- 
zación Mundial de la Salud, de todo Estado que no sea Miembro de la Organización Mundial de la Salud pero sea miembro de las Naciones Unidas, así como de las organizaciones de integración económica regional, en la sede de la Organización Mundial de la Salud, en Ginebra, desde el 16 de junio de 2003 hasta el 22 de junio de 2003, y posteriormente en la Sede de las Naciones Unidas, en Nueva York, desde el 30 de junio de 2003 hasta el 29 de junio de 2004.

\section{Artículo 35}

\section{Ratificación, aceptación, aprobación,} confirmación oficial o adhesión

1. El Convenio estará sujeto a la ratificación, aceptación, aprobación o adhesión de los Estados y a la confirmación oficial o la adhesión de las organizaciones de integración económica regional. Quedará abierto a la adhesión a partir del día siguiente a la fecha en que el Convenio quede cerrado a la firma. Los instrumentos de ratificación, aceptación, aprobación, confirmación oficial o adhesión se depositarán en poder del Depositario.

2. Las organizaciones de integración económica regional que pasen a ser Partes en el Convenio sin que lo sea ninguno de sus Estados Miembros quedarán sujetas a todas las obligaciones que les incumban en virtud del Convenio. En el caso de las organizaciones que tengan uno o más Estados Miembros que sean Partes en el Convenio, la organización y sus Estados Miembros determinarán su respectiva responsabilidad por el cumplimiento de las obligaciones que les incumban en virtud del Convenio. En esos casos, la organización y los Estados Miembros no podrán ejercer simultáneamente derechos conferidos por el Convenio.

3. Las organizaciones de integración económica regional expresarán en sus instru- mentos de confirmación oficial o de adhesión el alcance de su competencia con respecto a las cuestiones regidas por el Convenio. Esas organizaciones comunicarán además al Depositario toda modificación sustancial en el alcance de su competencia, y el Depositario la comunicará a su vez a las Partes.

\section{Artículo 36}

\section{Entrada en vigor}

1. El presente Convenio entrará en vigor al nonagésimo día contado desde la fecha en que haya sido depositado en poder del Depositario el cuadragésimo instrumento de ratificación, aceptación, aprobación, confirmación oficial o adhesión.

2. Respecto de cada Estado que ratifique, acepte, apruebe el Convenio o se adhiera a él una vez satisfechas las condiciones relativas a la entrada en vigor establecidas en el párrafo 1 del presente artículo, el Convenio entrará en vigor al nonagésimo día contado desde la fecha en que el Estado haya depositado su instrumento de ratificación, aceptación, aprobación o adhesión.

3. Respecto de cada organización de integración económica regional que deposite un instrumento de confirmación oficial o de adhesión, una vez satisfechas las condiciones relativas a la entrada en vigor estipuladas en el párrafo 1 del presente artículo, el Convenio entrará en vigor al nonagésimo día contado desde la fecha en que la organización haya depositado su instrumento de confirmación oficial o de adhesión.

4. A los efectos del presente artículo, los instrumentos depositados por una organización de integración económica regional no se considerarán adicionales a los depositados por los Estados Miembros de esa organización. 


\section{Artículo 37 \\ Depositario}

El Secretario General de las Naciones Unidas será el Depositario del Convenio, de las enmiendas de éste y de los protocolos y anexos aprobados de conformidad con los artículos 28, 29 y 33.

\section{Artículo 38}

Textos auténticos

El original del presente Convenio, cuyos textos en árabe, chino, español, francés, inglés y ruso son igualmente auténticos, se depositará en poder del Secretario General de las Naciones Unidas.

EN TESTIMONIO DE LO CUAL los infrascritos, debidamente autorizados a esos efectos, han firmado el presente Convenio.

HECHO en GINEBRA el 21 de mayo de dos mil tres. 